\title{
A Review Critical: Impact Assessment of Janani Surakshya Yojana (JSY) in Terms of, Knowledge, Attitude and Service Utilization Pattern of Women Beneficiaries
}

\author{
Naaz Bano $^{1 *}$, Rajesh Dahiya ${ }^{1}$ and Arti Kumari ${ }^{2}$ \\ ${ }^{1}$ Department of Extension Education and Communication Management, \\ ${ }^{2}$ Department of Human Development and Family Studies, CCS HAU, Hisar, India \\ *Corresponding author
}

\section{Keywords}

Pregnant women,

Antenatal care,

Mortality,

Morbidity and

Postnatal care

\section{Article Info}

Accepted:

25 November 2020

Available Online:

10 December 2020

\section{A B S T R A C T}

India has a appallingly high maternal death rate and infant mortality rate (IMR) of every 100000 births. In India the Maternal Mortality rate was 254 per 100000 live births in 2005, which has been reduced to 174 per 100000 live births in 2015. Maternal Mortality rate of Bihar per 100000 live births was 312 in 2005, which has been reduced to 208 in 2016. (World Bank, sample registration system).In India the Infant Mortality rate was 58 per 1000 live births in 2005, which has been reduced to 34 deaths per 1000 live births in 2017. To accomplish these objectives,, the National Rural Health Mission (NRHM) was launched in 2005, which intended to undertake an 'architectural correction' of the public health system, to empower it to successfully absorb increased expenditure to provide accessible, affordable and accountable in primary health care services to poor households in remote parts of rural India. The expected outcome of the mission is to make accessibility and availability of trained community level worker at village level with a generic medication unit. This signifies 'People's Health in People's Hand' with more of community involvement and community monitoring of public health system. The NRHM executed the Janani Surakshya Yojana (JSY) for the Below Poverty Line (BPL) families which provide referral transport and improved clinical care at subsidized rate for the institutional deliveries. The Janani Surakshya Yojana was embarked by the Hon'ble Prime Minister on12th April, 2005 and being executed in all the states and union territories with special extraordinary focus on Low Performing States (LPS). The JSY gives advantages for delivery and post-delivery care and it is completely centrally sponsored scheme. Achievement of the scheme is calculated by the increase in institutional delivery amongst the poor families.

\section{Introduction}

Janani Suraksha Yojana -JSY (In Hindi Language, Janani Mother, Suraksha
=Protection, Yojana = Scheme).The fundamental objectives of JSY scheme were to reduce Maternal Mortality Rate (MMR) and Infant Mortality Rate (IMR) through 
encouraging women for institutional deliveries; specially in below poverty line families. Under this scheme cash incentives are given to women who decided for institutional deliveries and also to the local health functionary who motivates and encourages the family for institutional delivery and causes them in obtaining antenatal and post-natal services. The principle components of the scheme are mobilizing the community with the help of intervention. In this scheme, the states where there is a low pace of Institutional deliveries is classified as 'Low Performing States (LPS) (Uttar Pradesh, Uttarakhand, Bihar, Jharkhand, Madhya Pradesh, Orissa, Chhattisgarh, Assam, Rajasthan and Jammu and Kashmir), though the remaining states are termed as High Performing States (HPS).

The recipients of JSY includes all women in both rural and urban areas, belonging to below poverty line matured 19 years or more, up to first two live births, SC/ST in the high performing states, while in low performing states, all women, including those from SC and ST families delivered in health centers, either government or accredited private health institutions will get the advantage. The program gives a continuum of care package that includes family planning, antenatal care, institutional delivery, postpartum care, and coordinated by the health care functionaries. (Reddy et al.,2016). JSY also entitlements free transportation between homes and health institutions, free provision of blood, free diets during stays at hospitals, drugs and consumables were provided to pregnant women and sick-new born who chose to undertake institutional delivery under proper healthcare facilities.

\section{Eligibility criteria for beneficiaries}

All pregnant women aged 19 years or above and belonging to either the SC/ST category or holding a BPL card can avail the benefits.
In low performing states Uttar Pradesh, Bihar, Assam, Jharkhand, Odisha, Chattisgarh, Jammu \& Kashmir, Uttarakhand, Madhya Pradesh and Rajasthan, as classified under the NHRM Program, JSY benefits are provided even after the third live birth

In high performing states such as Himachal Pradesh Haryana and Punjab, JSY benefits are restricted only up to two live births.

All beneficiaries need to have a bank account as cash assistance is undertaken only through cheque payments. With regard to the achievements of the scheme, JSY has been fruitful to over a lakh of pregnant women.

The scheme has ASHA as a vital functionary for providing services and functioning as a connection between healthcare delivery systems and the pregnant women. Each recipient enlisted under the scheme receives cash assistance for institutional delivery irrespective of independent of equality and socioeconomic status. The ASHA also additionally gets money help for accompanying the pregnant women to the institution (referral transport) and cash incentive after postnatal visit and bacille Calmette-Guerin (BCG) immunization of the child. (Doke et al.,2015)

Under this scheme cash incentives are given to women who decide for institutional deliveries and also to the local health functionary i.e. ASHA (Accredited Social Health Activists) who spurs the family for institutional delivery and helps them in obtaining ante-natal and post-natal services. (In Hindi language, "ASHA" in a real sense signifies "Expectation"). The NRHM raised a framework of prepared women community health workers, called ASHAs (Accredited Social Health Activists), who play significant role in execution of the Janani Suraksha Yojana scheme at the grassroots level. (Gupta et al., 2011). 
Keeping in view the importance of Janani Suraksha Yojana scheme for pregnant women this review paper has following specific objectives;

To review the knowledge and attitude of women beneficiaries towards JSY scheme,

To review the service utilization pattern by women beneficiaries under JSY scheme,

To review the impact of JSY scheme on institutional delivery.

\section{Knowledge and Attitude of Women Beneficiaries towards JSY Scheme}

Khatib et al., (2009) found that only 92 (33.6 per cent) pregnant women had undergone the minimum number of suggested antenatal check-ups during their present pregnancy. A minimum of 3 or more antenatal care visits 2 doses of tetanus toxoid/booster and at least 100 iron and folic acid tablets. Only 22 (7.5 per cent) enrolled in the third trimester had gone through 3 antenatal checkups had undergone 3 antenatal checkups as compared to 133 (48.3 per cent) and 85 (30.8 per cent) women enrolled in the first trimester and second trimester, respectively.

Lim et. al. (2010) in their investigation covering 593 districts of India, found that less than $5 \%$ of women are receiving monetary help from JSY in 141 districts. More than or equal to $30 \%$ in 128 districts. Highest level of receipt of cash assistance was recorded in Madhya Pradesh (44\%) and Lowest in Uttar Pradesh (7\%). Study did not find huge impact of JSYon maternal mortality at the district level. Study ascribes the absence of effect of JSY on maternal deaths to lack of programme effect or inadequate example size. The impact of monetary help from JSY on perinatal and neonatal deaths was smaller in High focus states (including $\mathrm{J} \& \mathrm{~K}$ ) than in Low focus states. Reduction in perinatal deaths in HFS was 2-3 per 1000 pregnancies. Reduction in perinatal deaths in low focus states was 5-6 per 1000 pregnancies. No state-specific effects were assessed.

Sidney et al., (2012) found that the majority of deliveries 76 per cent took place within the JSY scheme in the study area. 81 per cent of all mothers below poverty line delivered in the JSY program. 90 per cent of the mother had prior knowledge of the JSY scheme. Most mothers reported receiving the cash incentive within two weeks of delivery.

Gyawali et al., (2013) In their research found that three quarters of the participants had right information with respect to knowledge regarding minimum numbers of antenatal visits to be done by a pregnant women. Almost two fifth participants know schedule of antenatal care visit and JSY schemes.

Solanki et. al., (2013) conducted a study a cross sectional study in the Jamnagar District of Gujarat with a total sample size of 400 respondents. The study showed that $89.50 \%$ of respondents were aware about JSY and $10.50 \%$ were not. The study recorded $89 \%$ institutional deliveries and $11 \%$ home deliveries. Among rural women who had delivery in the hospital, majority of the women had received full cash incentive and only 22 per cent did not received monetary benefit as per scheme. The results of the study pointed out "supportive nature of ASHA" and "safety of the infant" as the motivational factors for opting institutional delivery in $100 \%$ of the respondents.

Regarding the awareness about the Janani Shishu Suraksha Karyakram Chatterjee et al., (2015) carried out a study and found that 68.75 per cent mothers had poor awareness regarding free entitlements of Janani Shishu Suraksha Karyakram and only 18.75 per cent 
mothers were aware about free normal delivery and free drugs and consumables. None of the respondents were aware about free caesarean section, free arrangement of blood for mother and sick infant. Each of 10.42 per cent respondents were aware about free treatment for sick infant and free drugs and consumables for sick infants. Overall 58.33 percent mothers were aware about free diet during stay in the health facilities. Parity of mother had significantly huge influence on the awareness level regarding JSSK.

Gaur (2015) in observational study in a tertiary care hospital in Madhya Pradesh using Hospital record as a secondary data source. Study reveals that institutional deliveries have increased by $31.76 \%$ immediately after the launch of JSY scheme. Perinatal deaths have decreased from 49 (2006) to 27 (2010) per 1000 total births. Thus study shows a significant impact of JSY on institutional deliveries, and has also significantly contributed to the reduction in neonatal and pre natal deaths.

The study conducted by Radhika et al., (2015) shows that majority of them 90 per cent have inadequate knowledge and 10 per cent have average knowledge regarding reproductive and child health services.67.5 per cent had knowledge regarding registration of pregnancy at first trimester, 42.5 per cent had minimum number of antenatal checkups knowledge, 60 per cent had knowledge about iron and folic acid, 57.5 per cent had about tetanus toxoid immunization and 50 per cent had knowledge about tests done during pregnancy.

Vinaya and Shantha (2015) in their study found that in respect of the knowledge about the JSY scheme, the majority of the antenatal mothers 61 per cent moderate knowledge, 36 per cent had poor knowledge, 2.5 per cent had very good knowledge and 0.5 per cent mothers had no good knowledge. With regard to the attitude of the respondents, 61.3 per cent of the respondents had positive attitude and 38.7 per cent of the respondents had negative regarding Janani Suraksha Yojana.

Regarding the knowledge about the JSY scheme Narwal et al., (2016) in their scheme found that the majority 55.66 per cent of antenatal mothers had moderate knowledge regarding JSY, 28.34 per cent had inadequate knowledge and only 16 per cent had adequate knowledge regarding JSY. With respect to the attitude towards JSY scheme, 81per cent of the women had positive attitude and 19 per cent of the women had negative attitude.

Nsemo and Offiong (2016) conducted a study and reported that there was low level of knowledge among rural women regarding the obstetric danger signs and the importance of hospital delivery among communities. The study suggested effective collaboration between the rural communities and health care professionals, for the intention of engaging the community to achieve the sustainability in health of rural women, their families and for the community. Importance of early recognition of obstetric dangers for, importance of utilizing skilled care during pregnancy, delivery and post partum for early intervention and the hazards of home delivery.

Patel et al., (2016) in this study entitled "knowledge about antenatal care among pregnant women" that reveals about 58 per cent women had adequate knowledge regarding antenatal care service provided by Government in the JSY scheme free of cost but 42 per cent women had poor knowledge about antenatal care service. 100 per cent women were having positive attitude towards antenatal care.

Radhika and Kasthuri (2016) showed that 95.5 per cent had knowledge regarding the minimum number of antenatal care visits. 76.3 
per cent regarding ideal time for first antenatal care visits and 23.7 per cent time for second antenatal care visits. 90.6 percent about time of first dose of tetanus toxoid immunization and 9.4 had knowledge about the timing of second dose of tetanus toxoid. Majority of them 67.9 per cent had moderately knowledge and 25.4 per cent had adequate knowledge and only 6.7 per cent inadequate knowledge with regard to practice of antenatal care services.

Reddy et al., (2016) conducted a study with the sample size of 120 postnatal mothers and found that, 78.3 per cent were aware of JSY scheme among which the majority 63.3 per cent came to know through the local Auxiliary Nursing Midwifery (ANM). Out of 120 mothers only 94 mothers were aware of JSY scheme and around 26 mothers were aware about institutional delivery benefits.

\section{The Service Utilization Pattern by Women Beneficiaries Under JSY Scheme}

Pal et al., (2008) observed that family planning counseling services utilized by the beneficiaries was 74 per cent. Regarding the antenatal period women get three antenatal check-ups 88 per cent, two doses of tetanus toxoids 89 per cent, iron and folic acid tablets 82 per cent and 61 per cent beneficiaries were checked for danger signs of pregnancies.

Kumar (2010) reported that only 66 per cent pregnant women received iron and folic acid tablets, 19 per cent received full course of 100 tablets, and only 15 per cent consumed 100 tablets during their pregnancy time.Buna et al., (2011) noted that among 248 mothers, 84 per cent mothers utilized the antenatal care services, 91per cent received tetanus toxoid vaccine during pregnancy. Most of them 80 per cent had institution delivery.

Sanjel et al., (2011) observed that the 78.9 per cent (153) antenatal visits were made by the women but only 46.4 per cent (71) completed four antenatal care visits. 61.4 per cent of first antenatal visit attainders completed the fourth visits and completed tetanus toxoid immunization.

Panja et al., (2012) in their study found that overall institutional delivery rate was 73.10 per cent and utilization of JSY among eligible women was 50.50 per cent institutional delivery (84.0 per cent), consumption of 100 iron-folic acid tablets (46.0 per cent) and three of more antenatal check-ups (91.0 per cent) were better in women who received financial assistance from Janani Suraksha Yojana scheme during antenatal period.

Sharma et al., (2012) conducted a study on an aggregate 2221 married women (15-49 years) out of which 1290 (58.08 per cent) women were from urban slums and 931 (41.92 per cent) women belonged to rural areas. 74.15 per cent women went registered with ASHA. Only 29.21 per cent went for three or more antenatal care visits. Only 48.31 per cent women consumed hundred iron and folic acid tablets and the extent was high (79.41 per cent) in rural women. All the women received complete tetanus toxoid immunization.

Dabade et al., (2013) concluded from the study that only 40.8 per cent women had their first antenatal visit in 1sttrimester. Majority of the women 90.3 per cent had institutional delivery.

Malik et al., (2013) observed that around onefourth of the mothers did not received recommended minimum three antenatal check-ups. The coverage of tetanus toxoid immunization was observed 92.10 per cent. Majority ( 90.4 per cent) of the deliveries were institutional. 84.6 per cent institutional deliveries were carried out in government institutions while 15.4 per cent deliveries were conducted in private hospitals. About two- 
third mothers received at least three post-natal care visits by the health functionaries.

Sahni and Sobti (2013) observed that 41.46 per cent antenatal women had received at least three antenatal check-ups. 86.74 per cent were found to be fully immunized with tetanus toxoid whereas intake of iron and folic acid tablets was recorded for only 32.62 per cent of the females. Overall, 29.12 per cent of the total pregnant women had received full antenatal care.

Vikram et al., (2013) interviewed 469 mothers and reported that 333 (71 per cent) had institutional delivery, 128 (27.3 per cent) had benefited from JSY scheme and 68 (14.5 per cent) had received monetary benefit of Janani Suraksha Yojana scheme and had more than six antenatal check-ups were the significant predictors of availing the benefits of Janani Suraksha Yojana scheme.

Coffey (2014) discovered that the Janani Suraksha Yojana, is a conditional cash incentive scheme to motivate women to give birth in health institutions. Despite the scheme's apparent success in increasing facility-based hospital delivery, the researcher had not found corresponding improvements in health outcomes of the rural women. The researcher analyzed data collected between January, 2012 and November, 2013 in a rural districts in Uttar Pradesh to address the question of why the scheme has not improved health outcomes among rural women. From the results of the study it was noted that health service providers are mainly focused on capturing economic rents associated with the program, and provide an extremely poor quality care to the rural women. Additional, the scheme had not provided beneficiaries net cash incentive at the time of delivery. Based on a comprehensive accounting of the monetary costs of hospital and home deliveries, the study found that the value of the transfer to rural women is small due to costs associated with hospital births. Finally, the study also recognized importance of emotional and psychological costs to rural women of delivering in the health institutions. The findings suggested the need for a considerable rethinking of the scheme, paying careful attention to incentivizing overall well being of the rural women and their child.

Shidhaye et al., (2014) conducted a study and reported that out of 73 rural women, it is evident that the antenatal care visits were very less.58 (89.5 per cent) women were registered during antenatal period 52(89.7 per cent) women received iron and folic acid tablets. 40(68.9 per cent) women registered for antenatal care received at least one tetanus toxoid immunization.

Trivedi et al., (2014) reported that 60 per cent beneficiaries from Primary Health Centers and 80 per cent beneficiaries from Community Health Centers received cash benefit within 1 st week after delivery whereas 100 per cent beneficiaries of district hospital and medical college hospital received cash benefit at the time of discharge.

Arora et al., (2015) concluded that 78.3 per cent females took antenatal and only 27.5 per cent females made 3 or more visits before delivery. According to the study beneficiaries who visited doctors and ANM consumed maximum iron tablets and had more institutional deliveries.

Kumar et al., (2015) reported that more than of the mothers had an institutional delivery and were eligible for the benefits under Janani Suraksha Yojana and nearly about half of the rural women $(49.45 \%)$ were benefited by free transport facility under JSY and 79.39 per cent were escorted by an ASHA worker and all of them received the monetary incentive after delivery in the public health facility under 
JSY. Nearly Around two-third (65.65 per cent) of the rural women beneficiaries had to expend some money at the public health service for buying medicines.

Sinha (2015) from his study found that the type of health service utilization of selected rural women of Uttrakhand revealed that an overall out of 313 respondents a highest proportion of $173(55.3 \%)$ had mostly availed governmental maternal health care services of Janani Suraksha Yojana involving minimum of 43.3 per cent in Haridwar district of Uttrakhand and maximum of 79.6 per cent in Almora district of Uttrakhand. Antenatal care services were examined by four indicators namely whether rural women had registered their pregnancy in their first trimester under JSY scheme, whether rural women had received antenatal checkups during first trimester in their pregnancy, whether they had received three or more antenatal check-ups, whether they had received two or more doses of tetanus toxic (TT) injection and whether they had received iron and folic acid tablets (IFA). The use of delivery care services was examined by the indicators namely, whether rural women went for institutional delivery, whether ASHA escorted to institution for delivery, whether monetary benefit was received after delivering in the institution, whether ever gone for post natal care checkups to any helath institutions within 42 days after delivery and whether ever counseled by health workers for rural women's own health and about child's health.

Baruah et al., (2016) found that 57.62 per cent women were registered themselves in the first trimesters, 57.98 percent had more than three antenatal care visits during their pregnancies and 65.97 per cent received full course of iron and folic acid tablets. 99.47 per cent had received at least one tetanus toxoid immunization. Utilization of ANC was good in illiterates and literates alike.
Bhimani et al., (2016) observed that 88.77 per cent of the rural women registered their pregnancy at either government office or any private hospital. Out of total registered women, 54.25 per cent had registered their pregnancy during 2nd trimester. Regarding to the frequency of antenatal visits, study showed that, 59.18 per cent rural women had availed more than three antenatal care visits. According to the results it was found that 81.92 per cent rural women had completed two doses of tetanus toxoid immunization. About 47 per cent of rural women had completed full course of iron and folic acid tablets. It was also observe that nearly half of the rural women had availed complete antenatal care (ANC) package.

Joshi et al., (2016) found that majority of mothers utilized the Janani Suraksha Yojana services, and 81.60 per cent rural women had delivered in hospitals. Majority of the rural women were registered (77\%), attended at least three antenatal visits (74 per cent), attended at least two postnatal visits (61.70 per cent), taken iron tablets (minimum 1 to 100 tablets) (58.70 per cent). The least percentage of the rural women had done hemoglobin test (43.9 per cent), HIV test (39.8 per cent) and completed their infants immunization (33.2 per cent). Whereas less percentage (18.36 per cent) of rural women were used family planning methods.

Kumar et al., (2016) noted that majority of the rural women were registered just after 2 weeks of pregnancy whereas 26.50 per cent rural women were registered with in first 12 weeks of pregnancy. Around 14.50 per cent rural women had not received at least three antenatal visits. 95.50 per cent rural women were received tetanus toxoid immunization, 88.50 per cent deliveries were institutional. and 54.5 per cent rural women received at least three postnatal care visits. Only 25.5 per cent mothers received cash incentive under 
Janani Suraksha Yojana. Patel et al., (2016) found that around 80 per cent women received antenatal care (ANC) under JSY scheme and 20 per cent didn't look for ANC. Overall, antenatal care registration was pretty good (92 per cent) but within first trimester it was only 58 per cent, tetanus toxoid immunization was observed 79 per cent and consumption of iron and folic acid tablets was found 76 per cent. According to the results of the study reason for inadequate utilization of antenatal care services under Janani Suraksha Yojana scheme was mainly due to either unawareness or financial constraints.

Thus it can be concluded that the JSY has increased the proportion of institutional deliveries in India, specifically among vulnerable populations. The lessons from the various researches and other available sources should be utilized to improve the performance of this scheme in India. The long-term financial and social investment in women's literacy would definitely add to the benefits under JSY in India. Therefore, the need of an hour is to make awareness among women through govt. publicity and awareness programmes at village and block level so that they can better utilize the benefits of JSY scheme. Moreover, targeting remote areas with special measures and emphasis on more and more antenatal care check-ups are the essential prerequisites to improve the effectiveness of the scheme.

\section{References}

Arora, A., Mittal, A., Sharma, B., Mehta, C., Pathania, D., Bunger, R. (2015). Antenatal care coverage role of health care provider, journal of Dental and medical sciences, 14(3):56-60.

Baruah, A., Baruah, B., Das, B.R. (2016).socio demographic factors affecting the antenatal care services utilization in Assam. Indian journal of basic and Applied Medical research, 5(2):796-804.

Bhimani, N.R., Vachhani, P.V., Kartha. G.P. (2016).Utilization pattern of antenatal health care services among married of reproductive age group in the rural area of surendranagar district, Gujarat, India: A community based crass sectional study. International journal of research in medical sciences, 4(1):252261.

Buna, B., Baburam, P., Bimala, B., Rajib, K.., Pokherl, A., Nilambar.J. (2011). Utilization of maternal health care services in belbari VDC of Eastern region of Nepal. Journal of Nobel medical college, 1(4):53-58.

Chatterjee, S., Das, D., Singh, R., Basu, A., Chakraborty, A., Ghosh, P.(2015). Awareness about Janani Shishu Suraksha Karyakram among pregnant mothers-a community based study in a rural area of West Bengal, India. IOSR Journal of Dental and Medical Science, 14(9):1-5.

Coffey, F. \& Finn, G. (2014). Janani Suraksha Yojana, India's "safe motherhood scheme. International Journal of Recent Scientific Research, 8(5):33343345.

Dabade, K.J., Dabade, S.K., Khadilkar, H.A. (2013). A study on utilization of maternal health café services in rural area of Aurangabad district Maharashtra. national journal of community medicine, 4(4):579-583.

Doke, P.P., Gawande, U.H., Deshpande, S.R., Gadgil, M. (2015). Evaluation of JSY in Maharashtra, India: Important lessons for implementation. International Journal of Tropical Diseases and health, 5(2):141-155.

Gaur A. (2015). Impact of Janani Suraksha Yojana on Institutional Delivery and Perinatal Death. Journal of Evidence based Medicine and Healthcare; 2 
(21): 3183-3189.

Gyawali, K., Paneru, D.P., Jnawali, B., Janawali, K. (2013).Knowledge and practices on maternal health care among mothers. A cross sectional study from rural areas of Midwestern development region Nepal. Journal of the scientific society, 40 (1):9-13.

Joshi, P., Mahalingam, G., Sorte, D. Y. (2016). Factors influencing utilization of maternal andchild health services among the postnatal mothers in hilly region, International Journal of Research in Medical Sciences, 4(6):2170-2176.

Khatib, N., Zahiruddin, Q.Z., Gaidhane, A.M., Waghmare, H. Srivastsava, T., Goyal, R.C., Zodpey, S.P., johrapurkar, S.R. (2009). Predictors for antenatal services and pregnancy outcome in rural area: A prospective study in Wardha district, Indiana journal of medical science, 63(10):436-444.

Kumar, R., Bachloo, T., bhardwa, A., Mukherjee, A.K. (2016). Utilization and perception of health services under JSY among mother in a rural area of Ambala district, Haryana. International journal of medical science and public health, 5(8): 16391643.

Kumar, S. (2010).Reducing maternal mortality in India. Policy, equity and quality issues. Indian Journal of Public Health, 54(2):57-64.

Kumar, V., Mishra, S.K, Kaushal, S.K., Gupta, S.C., Maroof, K.A. (2015). JSY: its utilization and perception among mothers and health care providers in a rural area of north India. International journal of medicine and public health, 5(2):165-168.

Kumar, V., Mishra, S.K., Kaushal, S.K., Gupta, S.C., Khan, A.M. (2015). A study on the effect of Janani Suraksha Yojana on Antenatal registration and institutional deliveries in the Agra district of Utter Pradesh. Indian journal of public health,59(1):54-57.

Lim, S. S. (2010). India's janani Suraksha Yojana- a conditional cash transfer programme to increase births in health facilities- An Impact Evaluation. The Lancet, 375.

Malik, J.S., Kalhan, M., Punia, A., Sachdeva, S., Behera, B.K., (2013). Utilization of health services under Janani Suraksha Yojna in Rural Haryana. International Journal of Medical and Public Health, 3(3):176-179.

Narwal, A., Bhardwaj, G., Devi, S. (2016). A descriptive study to assess the knowledge among the antenatal mothers regarding Janani Suraksha Yojana in a selected hospital of Bhopal, Madhya Pradesh. Asian Journal of Nursing Education and Research,6(3):377-380.

Nsemo, A.D and Offiong, D.J. (2016). Knowledge of obstetric danger signs among women of child bearing age in the rural communities of cross river state, Nigeria. International Educational Scientific Research Journal, 2(12):21-38.

Pal, D.K., Toppo, N., Tekhre, Y.H., Das, J.K., Bhattacharya., Mehon, S., Nandan, D.(2008). An appraisal of janani sahyogi yojna in the state of Madhya Pradesh. Health and population, 31(2):85-93.

Patel, B.B., Gurmeet, P., Sinalkar, D.R., Kapil, H., Pandya, A.M., Singh, N. (2016).Knowledge about antenatal care among pregnant women. Medical Journal of Dr.D.Y.Patil University,9(3): 354-362.

Patel, P., Patel, N., Shah,Y., Patwa, J., Kedia, G.(2016). Study to assess the extent of maternal health care utilization by women residing in urban slum area in Ahmadabad. International journal of 
medical science and public health, 5(3): 459-462.

Radhika, M and Kasthuri, G. (2016). Knowledge and practice of antenatal services among multipurpose health workers. International Journal of Applied Research, 2(2):162-168.

Radhika, M., Krishna, A.V., Indira, S. (2015). Knowledge and utilization practices of reproductive and child health services among mothers. International Journal of Applied Research, 1(8):428-432.

Reddy, N.R., Kishore, S.G., Viswanatha, P.G., Ranganath, T.S., Shanmugapriya, D.(2016). A study to assess the knowledge and utilization of JSY among postnatal mothers attending the urban health centre of Bangalore medical college and research institute. International Journal of Community Medicine and Public Health, 3(2): 512-516.

Sahni, B. and Sobti, S. (2013). Utilization of antenatal care among pregnant females registered at sub centre level in a rural area of Jammu in India. International journal of healthcare and biomedical research, 1(4):269-278.

Sanjel, S., Ghimire, R.R., Pun, K. (2011). Antenatal care practices in Tamang community of hilly area in central Nepal. Kathmandu university medical Journal, 9(2): 57-61.

Sharma., Kishore, S., Gupta, S.K., Semwal. (2012). Effects of JSY (A maternity benefits scheme) up-on the utilization of antenatal care services in rural and urban -slums communities of
Dehradun. National journal of community medicine, 3(1): 129-137.

Shidhaya, P.R., Nagaonkar, S.N., sidhaya, R.R. (2014).study of utilization of maternal health care services by rural women in tertiary care teachings hospital. Indian medical Gazette.PP:74-78.

Sinha, A. (2015). New empirical evidence for maternal health care: case of JSY in Uttarakhand, India. Journal of health systems, 1(1):38-47.

Solanki, H. R. (2013). Assessment of Janani Suraksha Yojana in Jamnagar District. International Journal of Research in Medical Sciences, 2(2), 109-112.

Trivedi, R., Adhikani, P., Singh, S. P., Singh, S., Nath, S., Saxena, M. (2014). Comparative evaluation of cash benefit scheme of JSY for beneficiary mothers from different health care settings of REWA district, Madhya Pradesh, India. Online journal of health and allied sciences 13(1):1-4.

Vikram, K., Sharma, A.K., Kannan, A.T. (2013). Beneficiary level factors influencing JSY utilization in urban slum population of trans-Yamuna area of Delhi. Indian journal medical research 1(38): 340-346.

Vinaya, K.T. and Shantha, K.K. (2015).Knowledge and attitude of mothers towards Janani Suraksha Yojana in a selected rural area of Mangalore, D.K., Karnataka. International Journal of Recent Scientific Research, 6(4):3406-3411.

\section{How to cite this article:}

Naaz Bano, Rajesh Dahiya and Arti Kumari. 2020. A Review Critical: Impact Assessment of Janani Surakshya Yojana (JSY) in Terms of, Knowledge, Attitude and Service Utilization Pattern of Women Beneficiaries. Int.J.Curr.Microbiol.App.Sci. 9(12): 3553-3562. doi: https://doi.org/10.20546/ijcmas.2020.912.422 